\title{
Lipoprotein Apheresis in the Treatment of Dyslipidemia - the Czech Republic Experience
}

\author{
V. BLÁHA ${ }^{1}$, M. BLÁHA ${ }^{2}$, M. LÁNSKÁ ${ }^{2}$, D. SOLICHOVÁ ${ }^{1}$, L. KUJOVSKÁ KRČMOVÁ ${ }^{1}$, \\ E. HAVEL ${ }^{3}$, P. VYROUBAL ${ }^{1}$, Z. ZADÁK ${ }^{1}$, P. ŽÁK ${ }^{2}$, L. SOBOTKA $^{1}$
}

${ }^{1}$ Third Department of Internal Medicine, Metabolism and Gerontology, University Hospital Hradec Kralove and Charles University Faculty of Medicine in Hradec Kralove, Czech Republic, ${ }^{2}$ Fourth Department of Internal Medicine, Hematology, University Hospital Hradec Kralove and Charles University Faculty of Medicine in Hradec Kralove, Czech Republic, ${ }^{3}$ Department of Surgery, University Hospital Hradec Kralove and Charles University Faculty of Medicine in Hradec Kralove, Czech Republic

Received October 31, 2016

Accepted December 19, 2016

\section{Summary}

In 1984, we started using therapeutic plasmapheresis (plasma exchange) as a method of extracorporeal lipoprotein elimination for the treatment of hypercholesterolemic patients. We evaluated the results of long-term therapy in 14 patients, 8 men and 6 women. The average age was $55.6 \pm 13.2$ (range 28-70), median 59.5 years. 14 patients were diagnosed with familial hypercholesterolemia (FH): 5 homozygous, 9 heterozygous. Ten patients in the group were treated using immunoadsorption lipoprotein apheresis and 4 using hemorheopheresis. Immunoapheretic interventions decreased LDL-cholesterol $(82 \pm 1 \%), A p o B(73 \pm 13 \%)$ and even $L p(a)$ by $82 \pm 19 \%$, respectively. Selected non-invasive methods are important for long-term and repeated follow-up. Carotid intima-media thickness showed improvement or stagnation in $75 \%$ of the patients. Biomarkers of endothelial dysfunction such as endoglin (in the control group: $3.85 \pm 1.25 \mu \mathrm{g} / \mathrm{l}$, in lipoprotein apheresis-treated hypercholesterolemic individuals $5.74 \pm 1.47 \mu \mathrm{g} / \mathrm{l}), \mathrm{CD} 40$ ligand (before lipoprotein apheresis: $6498 \pm 2529 \mathrm{ng} / \mathrm{l}$, after lipoprotein apheresis: $4057 \pm 2560 \mathrm{ng} / \mathrm{l}$ ) and neopterin (before lipoprotein apheresis: $\quad 5.7 \pm 1.1 \mathrm{nmol} / \mathrm{l}$ after lipoprotein apheresis: $5.5 \pm 1.3 \mathrm{nmol} / \mathrm{l}$ ) related to the course of atherosclerosis, but did not reflect the actual activity of the disease nor facilitate the prediction or planning of therapy. Hemorheopheresis may improve blood flow in microcirculation in familial hypercholesterolemia and also in some other microcirculation disorders via significantly decreased activity of thrombomodulin $(p<0.0001)$, tissue factor $(p<0.0001)$, aggregation of thrombocytes $(p<0.0001)$ and plasma and whole blood viscosity $(p<0.0001)$. In conclusion, lipoprotein apheresis and hemorheopheresis substantially lowered LDL-cholesterol in severe hypercholesterolemia. Our experience with long-term therapy also shows good tolerance and a small number of complications (6.26 \% non-serious clinical complications).

\section{Key words}

Cholesterol - Lipoprotein apheresis - Atherosclerosis • Biomarkers

\section{Corresponding author}

V. Bláha, Third Department of Internal Medicine, Metabolism and Gerontology, University Hospital Hradec Králové and Charles University Faculty of Medicine in Hradec Králové, Sokolská 581, 50005 Hradec Králové, Czech Republic. Fax: +420 495832001. E-mail: blaha@lfhk.cuni.cz

\section{Introduction}

Lipoprotein apheresis (LA) is a procedure that attempts to selectively remove atherogenic lipoproteins, thereby reducing cardiovascular events in patients who are affected by severe hypercholesterolemia and resistant to drug therapy (Wang et al. 2016). In patients with familial hypercholesterolemia (FH) who undergo lipoprotein apheresis, LDL-C levels are significantly reduced (Graesdal et al. 2012) and these high-risk 
patients benefit from this treatment option. Cardiovascular events can be reduced in homozygous $\mathrm{FH}$ patients (Keller 2009), and cardiovascular morbidity and mortality can be significantly reduced in heterozygous FH (Mabuchi et al. 1998). A meta-analysis of coronary angiographic trials, including studies of the use of diet, lipid-lowering drug therapy or apheresis, showed that apheresis might be more effective in reducing the progression of coronary heart disease (Thompson 2008). LA retards the progression and even induces the regression of advanced atherosclerotic lesions, not only by decreasing the number of circulating atherogenic lipoprotein particles but also by affecting its composition and oxidisability (Kopprasch et al. 2009, Stefanutti et al. 2001).

LA provides extracorporeal LDL elimination performed in repeated cycles with continuous blood flow. It is used in the treatment of high-risk patients to reach treatment goals in addition to maximally tolerated lipidlowering (combined) medication. Several methods of LA have been described (Bambauer et al. 2003, Bláha M. 2003, Julius et al. 2013, Pokrovsky et al. 2016, SchuffWerner 2003). Our working group uses immunospecific LA and hemorheopheresis, which is our own modification of classic double plasma filtration (Bláha et al. 2009). At present, therapeutic hemaphereses are performed at 7 university centers in the Czech Republic. Therapeutic aphereses are performed to accommodate a broad spectrum of indications (plasma exchange, leukapheresis, erythrapheresis, platelet apheresis, photopheresis and various types of adsorption including ABO mismatch for transplantations) either as routine procedures or in research projects. Extracorporeal cholesterol elimination is used at two of these centers (Institute for Clinical and Experimental Medicine, Prague and University Hospital, Hradec Králové).

\section{Patients and Methods}

Fourteen patients, 8 men and 6 women, were treated using long-term lipoprotein apheresis. The average age was 55.6 \pm 13.2 (range 28-70), median 59.5 years. All of the patients, including homozygous patients, were treated by secondary prevention. The clinical phenotype of $\mathrm{FH}$ is characterized by increased plasma levels of TC and LDLC, tendinous xanthomata and premature symptoms of CVD. The MedPed criteria were applied (Williams et al. 1993) using cut-off points for TC and LDLC levels above $95 \%$ of the Czech population (Šamánek and Urbanová 1997), age and family history of CVD. DNA-based evidence of a mutation in the $L D L R$ gene was the criterion for homozygous FH. None of the patients had a mutation in the $A P O B$ gene. All patients were treated daily with statins (rosuvastatin $40 \mathrm{mg}$ or atorvastatin $80 \mathrm{mg}$ ), 1 patient in combination with fenofibrate $(160 \mathrm{mg})$, 2 patients in combination with bile acid-binding resins $(6 \mathrm{mg})$, all patients in combination with ezetimibe (10 mg), and 5 patients with PCSK9 inhibitors. The patients were regularly treated with LDL apheresis (immunoadsorption - 10 patients) or rheohemapheresis (cascade filtration - 4 patients) for 4-20 years (average $11.3 \pm 5.3$ years), median 10.5 years. LA is considered a safe procedure in the hands of experienced personnel. Adhering to the rules, there were only $6.26 \%$ non-serious complications in our patient group (Bláha et al. 2007). The side-effects of lipoprotein apheresis we observed included early side-effects of vascular origin (hematoma at the access site, totally unsuccessful blood sampling), cardiovascular effects (hypotension, short-term vaso-vagal reaction including syncope), exchange solution effects (citrate toxicity - facial paresthesia, muscular tension) as well as other reactions (general signs - malaise, nausea, neurovegetative lability, chills, fever, headache, difficulties caused by the rigid position assumed during the procedure). Late side effects were not observed.

A group of 13 normolipidemic healthy subjects, 7 males and 6 females, aged 47 \pm 11 (range 25-60 years) without any known serious pathology served as the control group.

Data concerning all procedures are regularly reported to the WAA Registry (World Apheresis Registry) and compared with other centers before publication of results (Mortzell et al. 2016).

\section{Lipoprotein apheresis}

Plasma separation was carried out using a CobeSpectra or Optia continuous centrifugal separator (Terumo, Lakewood, Co, USA) in 10 patients. An adsorption-desorption automatic device (Adasorb, Medicap, Germany) controlled repeated fillings and washings of Lipopak adsorbers (Pocard, Moscow, Russia). In 2 patients, Lipocollect adsorbers (Medicollect, Germany) were used. Our desired LDL-C target level was below $1 \mathrm{mmol} / 1$ after apheresis. However, we now consider a target level of $0.5 \mathrm{mmol} / \mathrm{l}$ after apheresis to be more effective in reducing cardiovascular risk. The 
procedure usually lasts $4 \mathrm{~h}$, which is still acceptable for patient tolerance.

\section{Rheohemapheresis}

Four patients simultaneously received long-term therapy for hypercholesterolemia and higher levels of fibrinogen. Plasma was collected using a Cobe-Spectra or Optia separator, again following high-speed centrifugation. It was then passed through a "second stage", consisting of a filter (Evaflux 4A, Kawasumi, Tokyo, Japan) with hollow fibres of ethylene-vinyl alcohol with holes of $0.03 \mathrm{~mm}$. We used the CF-100 (Infomed, Geneva, Switzerland) as a secondary device. Plasma flow was continuous. Anticoagulation was secured with heparin and ACD-A (Baxter, Munich, Germany). The basic amount of processed plasma ( $1.5 \mathrm{x}$ body volume) was calculated by the blood cell separator computer based on weight, height and hematocrit.

\section{Laboratory investigations}

Samples were collected immediately before and after lipoprotein apheresis or hemorheopheresis and stored frozen at $-40{ }^{\circ} \mathrm{C}$.

Serum total cholesterol, low-density lipoprotein (LDL) cholesterol, high-density lipoprotein (HDL) cholesterol, lipoprotein (a) and triacylglycerols were determined using a commercial kit (Roche) on the modular Roche analyzer (Roche Diagnostics $\mathrm{GmbH}$, Mannheim, Germany) according to the manufacturer's instructions.

Endoglin, hsCRP and CD40L levels were measured using a commercial Quantikine ${ }^{\circledR}$ human sandwich ELISA assay ( $\mathrm{R} \& \mathrm{D}$ Systems, Minneapolis, MN, USA). LDL in serum was measured using the 2nd generation Roche (Basel, Schwitzerland) LDL-C diagnostic kit. This kit fulfilled the validation requirements of European Directive 98/79 and is assigned the CE mark of conformity.

Neopterin was measured in the urine specimens using a reversed-phase high performance liquid chromatography system (Hewlett-Packard, Palo Alto, USA). Potassium phosphate buffer (15 mmol/1, $\mathrm{pH} 6.4$ ) at a flow-rate of $0.8 \mathrm{ml} / \mathrm{min}$ was used as the mobile phase. Neopterin was identified by its native fluorescence (353 nm excitation, $438 \mathrm{~nm}$ emission), the MPF-3 detector (Perkin-Elmer, Norwalk, USA) and quantified using an external standard.

The level of $\alpha$-tocopherol in erythrocyte membranes was analyzed using a modified HPLC method.

Platelet functions were evaluated using modern methods of analysis. In vitro examination was carried out from citrate whole blood under conditions simulating arterial blood flow (laminar flow of the sample along the polystyrene surface of the dish) to evaluate thrombocyte adhesion: (SC) \% of the dish surface covered with thrombocytes and thrombocyte aggregates; (AS) the size of newly developed aggregates (Impact-R - DiaMed, Cressier, Switzerland).

Ultrasound carotid intima media thickness (CIMT) and computed tomography using a coronary calcification score were performed in a routine clinical setting.

\section{Statistical analysis}

SigmaStat for Windows Version 3.0 (SPSS Inc., San Rafael, USA) was used for statistical evaluation of changes in each measured parameter before and after extracorporeal elimination therapy. Evaluations were carried out using the nonparametric Mann-Whitney U-test and the Wilcoxon signed-rank test. Statistical significance was based on $\mathrm{P}<0.05$.

\section{Results}

\section{Clinical effects of lipoprotein apheresis}

We first began extracorporeal LDL-cholesterol elimination using therapeutical plasmapheresis (plasma exchange) in 1984. The method involves the exchange of one (or more) body volume(s) of plasma, usually using albumin as a replacement solution. Although it has been shown to be non-specific, plasmapheresis is still used as a rescue method in emergencies and hypertriglyceridemic crises. It has also proved useful as an initial treatment for serious hypercholesterolemia over time before starting more specific treatment. In a homozygote patient treated by us, initial total cholesterol values of $23 \mathrm{mmol} / \mathrm{l}$ dropped by one half during initial plasmapheresis. However, subsequent specific elimination with immunoadsorption proved much more effective.

Our group consisted of 14 long-term treated patients comprising 8 men and 6 women. Apheretic interventions lowered LDL-cholesterol, ApoB and even Lp(a) by about $82 \pm 1 \% ; 73 \pm 13 \%$; and $82 \pm 19 \%$, respectively. To maintain the decreased mean values, interventions had to be carried out every $18 \pm 2$ days on average. The desirable interval for performing LA in 
homozygous familial hypercholesterolemic patients is every week; for others, it is ideally every other week. Hemorheopheresis is nearly as effective as LDL-apheresis. Moreover, it can lower fibrinogen, viscosity and increase blood flow in microcirculation, even for critical ischemia of the extremities.

The main goal of LA therapy is to reduce cardiovascular morbidity and mortality. Nobody in our group of long-term treated patients died of atherosclerotic complications (one died due to carcinoma of the urinary bladder) after treatment using LA. One patient with homozygous familial hypercholesterolemia suffered from myocardial infarction and underwent coronary bypass surgery; another patient with homozygous familial hypercholesterolemia suffered from significant aortic stenosis and underwent surgical replacement of the aortic valve and aortic arch. Xanthomas disappeared within 9 months after LDL apheresis in patients affected by homozygous familial hypercholesterolemia.

Selected non-invasive methods are important for long-term and repeated follow-up. To monitor atherosclerotic cardiovascular pathology, we performed an ultrasound examination of the heart, ultrasound carotid intima media thickness (CIMT) and monitoring of carotid atheromas, or computed tomography with a coronary calcification score. For example, CIMT showed improvement or stagnation in $75 \%$ of patients.

During December 2012, one patient with homozygous familial hypercholesterolemia treated over the long-term using LA gave birth to a healthy child (boy). Rare cases of pregnancy in women with homozygous familial hypercholesterolemia (HoFH) have been reported (for a review, see Blaha V. et al. 2015). HoFH may pose significant risks for the mother and her fetus. Statins or PCSK9 inhibitors, the most potent agents for low-density lipoprotein cholesterol reduction, are contraindicated; thus, lipoprotein apheresis remains the only effective treatment. One woman with HoFH was treated throughout the entire pregnancy by lipoprotein apheresis (immunoadsorption method). Increasing levels of LDL-C were stabilised at $9-10 \mathrm{mmol} / \mathrm{l}$ by lipoprotein apheresis (performed every 10 days). No complications were observed during the treatment procedures. Monitoring of the fetus revealed no impairment of the umbilical cord and blood flow in the uterine arteries, or any intrauterine growth retardation. The delivery was spontaneous and child breast feeding was complete after two months. We then continued with LDL-apheresis performed every 10 days. Thereafter, the patient resumed medicamentous therapy (statin, ezetimibe) once breastfeeding was finished.

\section{Biomarkers and lipoprotein apheresis}

Some acute phase proteins (C-reactive protein, serum amyloid A, interleukin-6, procalcitonin or fibrinogen) as well as neopterin, an indicator of systemic immune activation, have been documented to be circulating biomarkers associated with atherosclerotic cardiovascular diseases. Neopterin (2-amino-4-hydroxy6-[D-erythro-6-(1,2,3-trihydroxypropyl)]-pteridine) is a metabolite of guanosine triphosphate, produced by macrophages upon stimulation with interferon-gamma and reflects macrophage activity (Table 1). We found that the urinary neopterin/creatinine ratio increased in hypercholesterolemic patients treated using LA compared to controls. No significant changes in the neopterin/ creatinine and albumin/creatinine ratios were observed after LDL-apheresis, except for a significant $(p<0.006)$ decrease in the urinary neopterin/creatinine ratio in the evening after apheresis. This decrease showed significant negative correlation with the pre-apheretic levels of atherogenic cholesterol fractions $(\mathrm{p}<0.05)$ and with cholesterol decrease during apheresis $(p<0.05)$. The urinary albumin/creatinine ratio correlated positively with total and LDL-cholesterol levels before apheresis and with the evening urinary neopterin/creatinine ratio after apheresis, but did not correlate with glycemia or triacylglycerides.

Soluble endoglin (sCD105), which is an indicator of endothelial dysfunction, may represent another biomarker of atherosclerosis. Mean serum concentration of soluble endoglin in the control group was $3.85 \pm 1.25 \mu \mathrm{g} / \mathrm{l}$, range $1.89-6.37 \mu \mathrm{g} / \mathrm{l}$, median $3.56 \mu \mathrm{g} / \mathrm{l}$. We found that in LA-treated hypercholesterolemic individuals baseline serum SCD105 levels were significantly higher in patients before the first lipoprotein apheresis $(5.74 \pm 1.47 \mu \mathrm{g} / \mathrm{l})$ than in the control group $(3.85 \pm 1.25 \mu \mathrm{g} / \mathrm{l}) \quad$ (Table 1). Soluble endoglin decreased to normal after LDL-elimination $(p<0.0005)$ in all except for one patient. This return to normal was not due to non-specific capture of endoglin in adsorption or filtration columns, as demonstrated by measurement of sCD105 before and after passage through the elimination media. We concluded that the soluble endoglin levels in patients with severe $\mathrm{FH}$ remain elevated despite long-term intensive therapy and that they decrease after extracorporeal elimination. 
Table 1. HsCRP, sCD40L, neopterin and endoglin in serum before and after the first lipoprotein apheresis.

\begin{tabular}{lcccccc}
\hline & \multicolumn{3}{c}{ Before lipoprotein apheresis } & \multicolumn{2}{c}{ After lipoprotein apheresis } \\
\cline { 2 - 7 } & Mean \pm SD & Range & Median & Mean \pm SD & Range & Median \\
\hline hsCRP $(\mathrm{mg} / \mathrm{l})$ & $1.88 \pm 1.71$ & $0.28-4.71$ & 1.00 & $1.32 \pm 1.52$ & $0.21-4.36$ & 0.71 \\
sCD4OL $(\mathrm{ng} / \mathrm{l})$ & $6498 \pm 2529$ & $3494-10500$ & 6395 & $4057 \pm 2560$ & $409-8375$ & 3576 \\
Neopterin $(\mathrm{nmol} / \mathrm{l})$ & $5.7 \pm 1.1$ & $4.2-7.3$ & 5.6 & $5.5 \pm 1.3$ & $4.3-8.8$ & 5.1 \\
Endoglin $(\mu \mathrm{g} / \mathrm{l})$ & $5.74 \pm 1.47$ & $3.33-7.65$ & 5.55 & $4.25 \pm 1.17$ & $2.49-6.28$ & 4.03 \\
\hline
\end{tabular}

SD - standard deviation.

Table 2. Changes of hsCRP, sCD40L, neopterin and endoglin in serum before and after the next lipoprotein apheresis in percentage of preapheretic values.

\begin{tabular}{lcccc}
\hline & \multicolumn{3}{c}{ Decrease (\%) } & p \\
\cline { 2 - 3 } & Average \pm SD & Range & Median & \\
\hline hSCRP & $37.7 \pm 10.7$ & $19.8-50.0$ & 40.0 & 0.002 \\
sCD 40L & $28.2 \pm 56.2$ & $-114.0-91.6$ & 37.7 & 0.014 \\
Neopterin & $1.8 \pm 74.1$ & $-194.7-63.0$ & 10.7 & 0.294 \\
Endoglin & $10.8 \pm 44.7$ & $-112.6-43.1$ & 20.9 & 0.038 \\
\hline
\end{tabular}

SD - standard deviation.

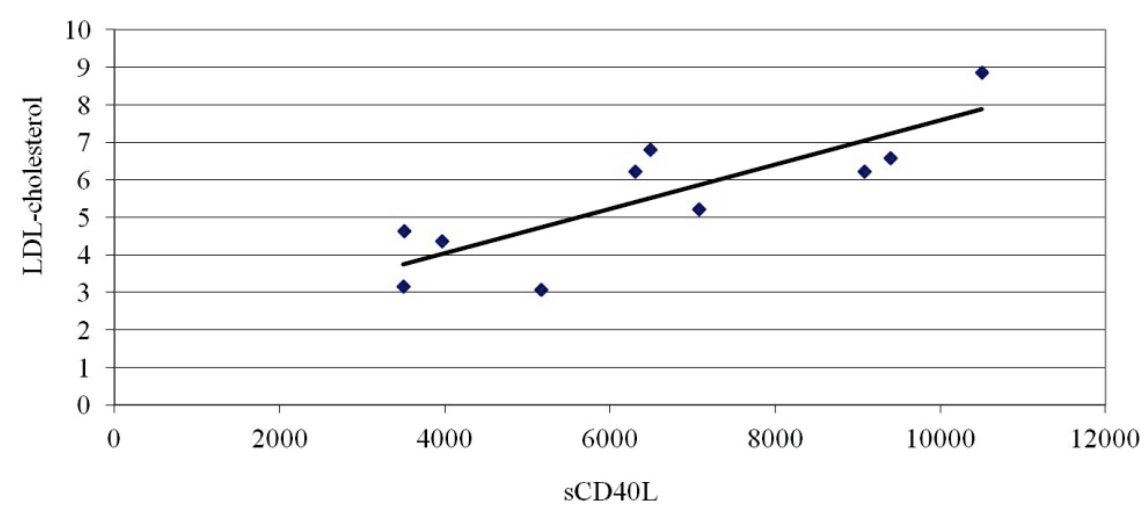

Fig. 1. Relation of serum CD40L ( $\mathrm{ng} / \mathrm{l})$ and LDL-cholesterol $(\mathrm{mmol} / \mathrm{l}) . \mathrm{r}_{\mathrm{s}}=0.818$, $\mathrm{p}=0.002$.

In addition to soluble endoglin, we studied, in the same patients, other immunologically active molecules, CRP and sCD40L. Both hsCRP and the SCD40L ligand decreased after lipoprotein apheresis (Table 1). The decrease of sCD40L significantly correlated with LDL-C (Fig. 1).

The relative changes of of hsCRP, sCD40L, neopterin and endoglin in serum before and after the next lipoprotein apheresis in percentages of pre-apheretic values are shown in Table 2.

Mean platelet volume is attracting increasing interest as a new independent cardiovascular risk factor. Large platelets are likely to be more reactive. If mean platelet volume were to drop after LDL-lowering therapy, decreased MPV could be one of the markers of successful therapy. Therefore, we investigated mean platelet volume in patients with severe familial hypercholesterolemia treated over the long-term (3-12 years) using LA (immunoapheresis) or cascade filtration. Mean platelet volume before the procedures was $10.891 \mathrm{fl}$, CI 10.25-11.53 and after the procedures decreased to 10.478 fl, CI 09.84-11.11 ( $<<0.05)$. Mean platelet volume did not correlate with age, sex, platelet count or duration of therapy.

Another aspect of the treatment by lipoprotein apheresis is its influence on the coagulation cascade, and this activation may play an important role in the development of atherosclerosis. We monitored the 
following parameters (pair sampling twice yearly before and after lipoprotein apheresis): thrombomodulin, platelet factor 4 (PF 4), immature platelet fraction, tissue factor (TF), $\beta$-thromboglobulin, fragments F1/F2, complex thrombin-antithrombin (TAT). Our results show that the activity of thrombomodulin $(\mathrm{p}<0.0001)$, tissue factor $(p<0.0001)$ and aggregation of thrombocytes $(p<0.0001)$ significantly decreases after plasma filtration. PF 4 (platelet factor 4), IPF (immature platelet fraction), TAT (thrombin-antithrombin complexes) and fragments F1/F2 did not change significantly. Simultaneously, we observed a decrease of plasma and whole blood viscosity in relation to decreased LDL-C, but also a decrease in some other high-molecular proteins. Simultaneous decrease of LDL-C and fibrinogen is desirable in patients with hyperfibrinogenemia, and can be attained by rheopheresis. These results and a final conclusion will be further interpreted once the measurements are extended.

\section{Antioxidant defence system and the effects of lipoprotein apheresis}

Oxidative stress is thought to play an important role in the pathogenesis of disorders associated with atherosclerosis. Alpha-tocopherol is considered to be an effective lipophilic antioxidant, which protects lipid membranes against peroxidation and thus prevents cell damage by reacting with free radicals. After lipoprotein apheresis, as a consequence of the induced marked reductions in lipoprotein, the patients' serum alphatocopherol levels decreased dramatically (Solichová et al. 2015, Ballard et al. 2016). Alpha-tocopherol decreases transiently based on hypolipidemic intervention. Absolute losses of alpha-tocopherol, which is considered to be the most biologically active of several forms of vitamin $\mathrm{E}$, amount to $13.4-22.5 \mathrm{mg} /$ apheresis and are equivalent to the recommended dietary intake for 1.5 to 2 days (Armstrong et al. 1988). However, measurement of alpha-tocopherol concentration in serum does not reflect the content of alpha-tocopherol in membranes, whereas erythrocyte alpha-tocopherol may be a good indicator of antioxidative status. Therefore, a simple isocratic reversed phase HPLC method has been developed and validated for the determination of alpha-tocopherol in human erythrocytes in a clinical setting (Solichová et al. 2015). We studied the content of alpha-tocopherol in the human erythrocyte membrane and lipoperoxidation in patients with severe hypercholesterolemia treated using lipoprotein apheresis. We compared the group of hypercholesterolemic patients $(\mathrm{n}=10)$ treated using lipoprotein apheresis to healthy adult normolipidemic controls. Treatment with lipoprotein apheresis significantly decreased the levels of alpha-tocopherol in serum and all lipoprotein fractions. The decrease in serum was $45 \%$, and levels in the various lipoprotein fractions decreased in the range of 31-61\%. Treatment with LA significantly increased the ratios of alpha-tocopherol to cholesterol lipoprotein fractions. The increase in serum was $43 \%$, in the LDL fraction $11 \%$ and in the VLDL fraction $22 \%$. The ratio of alpha-tocopherol to particular lipoproteins decreased slightly only in the HDL fraction by $4 \%$. The content of erythrocyte membrane alphatocopherol did not change significantly. After LA, we observed significantly decreased serum thiobarbituric acid reacting substances (TBARS - markers of lipoperoxidation) $(\mathrm{p}<0.001)$, which increased from the third day thereafter and remained significantly higher in comparison to controls until the next lipoprotein apheresis $(p<0.001)$. The changes in LDL-bound tocopherol and TBARS correlated significantly $(\mathrm{p}<0.001)$.

\section{Discussion}

Our results show that lipoprotein apheresis and hemorheopheresis are effective methods for treating patients with severe hypercholesterolemia, who, through changes to lifestyle, diet or intensive drug therapy, have failed to lower LDL-C sufficiently. Therapy using lipoprotein apheresis can be a lifesaving measure in homozygotes and slows down the progress of atherosclerotic cardiovascular disease in FH heterozygous and other hypercholesterolemic patients. Recently, the Czech Society of Atherosclerosis established a multidisciplinary working group for the provision of LA in the Czech Republic. Its main purpose is to promote the accessibility of LA for Czech patients. The group has also defined the selection criteria for LA (Bláha V. et al. 2015). Broader use of this therapy has not come to pass mainly due to financial conditions. Follow-up of patients using ultrasound examination of the heart, ultrasound carotid intima media thickness (CIMT) and monitoring of carotid atheromas, or computed tomography with a coronary calcification score was approved as being very useful (Bláha et al. 2008a). Treatment using LA may enable acceptable lipoprotein levels to be maintained even without medicamentous therapy (which is contraindicated) and even in pregnant ladies with HoFH. We reported on a 34-year-old pregnant woman with 
HoFH who was treated throughout her entire pregnancy using lipoprotein apheresis (immunoadsorption method) (Bláha M. et al. 2015).

Increased circulating levels of various biomarkers have been associated with atherosclerotic cardiovascular diseases (Erren et al. 1999). In extracorporeal elimination therapy, there are currently no universally accepted biomarkers that can determine the necessary intensity of therapy or the frequency of future therapeutic interventions. An ideal tool for immediate evaluation would be a readily measurable serum marker. We have measured and further discussed the role of some adhesive molecules, cytokines (Bláha M. et al. 2003), endoglin (Bláha et al. 2008b), mean platelet volume (Bláha et al. 2013) and the evaluation of platelet aggregation (Bláha et al. 2004).

Among the biomarkers associated with atherosclerotic cardiovascular diseases in LA treatment, measurement of neopterin concentrations may be used to assess macrophage activity. Neopterin production may reflect oxidative stress caused by immune system activation (Wachter et al. 1989). We have found that the urinary neopterin/creatinine ratio increases in hypercholesterolemic patients treated using LA compared to controls (Cermanová et al. 2005). Elevated urinary neopterin in patients with severe primary lipoprotein disorders reflects the presence of atherosclerosis. The correlations between microalbuminuria, neopterin and pre-apheretic cholesterol concentrations indicate a possible connection between microvascular dysfunction, macrophage activity and severity of hyperlipidemia (Cermanová et al. 2005). A soluble form of endoglin (sEng) is known to be an extracellular domain of the full-length membrane endoglin, which is elevated during various pathological conditions related to vascular endothelium (Rathouská et al. 2015).

Hypercholesterolemia is one of the most studied risk factors resulting in endothelial dysfunction and atherosclerosis. The relation of cholesterolemia and sEng was first referenced in a study by Blann et al. (1996), who demonstrated increased serum levels of sEng in patients with atherosclerosis. They found it to be associated with total cholesterol levels but not with other markers of endothelial damage or dysfunction, e.g. E-selectin. The elevation of sEng levels was also related to atherosclerotic plaque morphology and correlated with unstable angina pectoris, acute myocardial infarction and post-infarction heart remodeling (Cui et al. 2008). Several papers also mention therapeutical interventions that affect soluble endoglin levels. We have shown that lipoprotein apheresis reduces levels of blood cholesterol particles followed by a reduction of sEng and other biomarkers of endothelial dysfunction (hs-CRP and sCD40L) in patients with familial hypercholesterolemia (Bláha et al. 2006). We have also concluded that the drop in sEng levels is not attributable to LDL apheresis itself, but to the decreased activity of endothelial cells and the immune system following the removal of atherogenic elements (Bláha et al. 2008a). In addition, Brownfoot et al. (2014) report that oxysterols increase sEng release from primary human tissues, but that pravastatin treatment has no effect on sEng levels.

Vitamin E components with antioxidant activity include alpha, beta and gamma-tocopherol and tocotrienols. Alpha-tocopherol is an effective lipophilic antioxidant, which protects lipid membranes against peroxidation. This vitamin is almost exclusively located in membranes (Combs 2008). We have shown that treatment using lipoprotein apheresis does not lead to the exhaustion of alpha-tocopherol reserves, because the cell membrane levels of alpha-tocopherol are maintained within pre-treatment levels even in patients who have been treated regularly using lipoprotein apheresis for several years (Bláha V. et al. 2015). Accordingly, the removal of alpha-tocopherol using lipoprotein apheresis does not accelerate atherosclerosis. It can be also concluded that no extra supplementation of this vitamin is required during lipoprotein apheresis therapy, although it may be advisable to monitor alpha-tocopherol status in patients on long-term, intensive therapy. Selective lipoprotein apheresis not only decreases the pool of LDL, but it also induces changes associated with alpha-tocopherol that render LDL less susceptible to oxidation, namely a decrease in TBARS. This interferes with other mechanisms of atherogenesis such as endothelial dysfunction, monocyte adhesion, cytokine production, etc. (Nakamura et al. 2003).

\section{Conclusion}

Lipoprotein apheresis as well as hemorheopheresis are established and proven methods for treating severe hypercholesterolemia. Its effects are mediated by a substantial decrease in the level of LDL-cholesterol, as well as other atherogenic lipoproteins. Moreover, it has been shown to improve other variables associated with progressive atherosclerosis such as endothelial dysfunction and 
oxidative stress. Hemorheopheresis may even improve blood flow in microcirculation in familial hypercholesterolemia and in some other microcirculation disorders. In our experience, long-term therapy results in good tolerance and acceptable minimal side effects. Recently, the Czech Society of Atherosclerosis has made efforts to promote the further rationalization and expansion of lipoprotein apheresis in the therapy of Czech patients.

\section{Conflict of Interest}

There is no conflict of interest.

\section{Acknowledgements}

This work was supported by project PRVOUK P37/12 of Charles University, Faculty of Medicine in Hradec Králové, 17-28882A MH CZ and $\mathrm{MH} \mathrm{CZ} \mathrm{-} \mathrm{DRO}$ (UHHK, 00179906)-8134, 8177.

\section{References}

ARMSTRONG VW, NIEDMANN D, EISENHAUER T, JANNING G, WAGNER H, SCHUFF-WERNER P, SEIDEL D: Acute and long-term effects of low-density lipoprotein apheresis on the serum concentrations of vitamins $\mathrm{E}$ and A. Klin Wochensch 66: 123-128, 1988.

BALLARD KD, MAH E, GUO Y, BRUNO RS, TAYLOR BA, BEAM JE, POLK DM, THOMPSON PD: Single lowdensity lipoprotein apheresis does not improve vascular endothelial function in chronically treated hypercholesterolemic patients. Int J Vasc Med 22: e4613202, 2016.

BAMBAUER R, SCHIEL R, LATZA R: Low-density lipoprotein apheresis: an overview. Therap Apher Dial 7: 391-396, 2003.

BLÁHA M: Extracorporeal LDL-cholesterol elimination in the treatment of severe familial hypercholesterolemia. Acta Med (Hradec Králové) 46: 3-7, 2003.

BLÁHA M, ANDRÝS A, BLÁHA V, KREJSEK J, SKOŘEPOVÁ M, FILIP S, MALÝ J, BLAŽEK M: Adhesive selectin molecules during extracorporeal cholesterol elimination. Hematol J 4: 23-24, 2003.

BLÁHA M, PECKA M, URBÁNKOVÁ J, BLÁHA V, MALÝ J, ZADÁK Z, BLAŽEK M: Activity of thrombocytes as a marker of sufficient intensity of LDL-apheresis in familial hypercholesterolaemia. Transfus Apher Sci 30: 83-87, 2004.

BLÁHA M, CERMANOVÁ M, BLÁHA V, BLAŽEK M, FILIP S, MALÝ J, ŠIROKÝ O, SOLICHOVÁ D, ŘEHÁČEK V: Safety and tolerability of LDL-apheresis in familial hyperlipoproteinaemia. Therapeutic Apher Dial 11: 9-15, 2007.

BLÁHA M, CERMANOVÁ M, BLÁHA V, JAROLÍM P, ANDRÝS C, BLAŽEK M, MALÝ J, SMOLEJ L, ZAJÍC J, MAŠÍN V, ZIMOVÁ R, REHÁČEK V: Elevated serum soluble endoglin (sCD105) decreased during extracorporeal elimination therapy for familial hypercholesterolemia. Atherosclerosis 197: 264-270, $2008 \mathrm{a}$.

BLÁHA M, ŠTRASOVÁ A, UNGERMAN L, BLAŽEK M, BLÁHA V, MALÝ J, MAŠÍN V: Significance of non-invasive cardiovascular examinations for the evaluation of extracorporeal LDL-cholesterol elimination efficacy. Abstract. Transfus Med Hemother 35: 80, 2008b.

BLÁHA M, ZADÁK Z, BLÁHA V, ANDRÝS C, HAVEL E, VYROUBAL P, BLAŽEK M, FILIP, S, LÁNSKÁ M, MALÝ J: Extracorporeal LDL cholesterol elimination (25 years of experience in CZ). Atheroscler Suppl 10: 17-20, 2009.

BLÁHA M, KOŠŤÁL M, LÁNSKÁ M, BLÁHA V, FORALOVÁ I, FILIP S, KUBIŠOVÁ M, MALÝ J: The decrease of mean platelet volume after extracorporeal LDL cholesterol elimination. Atheroscler Suppl 14: 77-81, 2013.

BLÁHA M, LÁNSKÁ M, BLÁHA V, BOUDYŠ L, ŽÁK P: Pregnancy in homozygous familial hypercholesterolemia importance of LDL-apheresis. Atheroscler Suppl 18: 134-139, 2015.

BLÁHA V, SOLICHOVÁ D, BLÁHA M, CERMANOVÁ M, ANDRÝS C, HYŠPLER R, VYROUBAL P, HAVEL E, ZADÁK Z: Extracorporeal LDL-cholesterol elimination - impact on the level of C-reactive protein (CRP), neopterin, endoglin and CD40 ligand (CD40L). Cor Vasa 48: 1, 2006.

BLÁHA V, BLÁHA M, LÁNSKÁ M, HAVEL E, VYROUBAL P, ZADÁK Z, VRABLÍK M, PIŤHA J, ŽÁK P, SOBOTKA L: Position of lipoprotein apheresis in present (in Czech). Vnitr Lek 61: 958-964, 2015. 
BLANN AD, WANG JM, WILSON PB, KUMAR S: Serum levels of the TGF-beta receptor are increased in atherosclerosis. Atherosclerosis 120: 221-226, 1996.

BROWNFOOT FC, HANNAN N, ONDA K, TONG S, KAIUTU'U-LINO T: Soluble endoglin production is upregulated by oxysterols but not quenched by pravastatin in primary placental and endothelial cells. Placenta 35: 724-731, 2014.

CERMANOVÁ M, MELICHAR B, SOLICHOVÁ D, BLÁHA M, BLÁHA V, BLAŽEK M, MAŠÍN V, CERMAN J, ZADÁK Z: Urinary neopterin and microalbumiuria in patients treated by low-density lipoprotein apheresis. Pteridines 16: 174-183, 2005.

COMBS GE: Vitamin A and vitamin E. In: The Vitamins. SEBRELL WH, HARRIS RS (eds), New York, 2008, pp 181-212.

CUI S, LU SZ, CHEN YD, HE GX, MENG LJ, LIU JP, SONG ZY, LIU XL, SONG XT, GE CJ, LIU H: Relationship among soluble CD105, hypersensitive C-reactive protein and coronary plaque morphology: an intravascular ultrasound study. Chin Med J Eng 121: 128-132, 2008.

ERREN M, REINECKE H, JUNKER R, FOBKER M, SCHULTE H, SCHUREK JO, KROPF J, KERBER S, BREITHARDT G, ASSMANN G, CULLEN P: Systemic inflammatory parameters in patients with atherosclerosis of the coronary and peripheral arteries. Arterioscler Thromb Vasc Biol 19: 2355-2363, 1999.

GRAESDAL A, BOGSRUD MP, HOLVEN KB, NENSETER MS, NARVERUD I, LANGSLET G, BREJLE M, RETTERSTOL K, ARBESEM KE, OSE L: Apheresis in homozygous familial hypercholesterolemia: the results of a follow-up of all Norwegian patients with homozygous familial hypercholesterolemia. J Clin Lipidol 6: 331-339, 2012.

JULIUS U, FISCHER S, SCHATZ U, PASSAUER J, BORNSTEIN S: Why an apheresis center should offer more than one lipoprotein apheresis method. Ther Apher Dia 17: 179-184, 2013.

KELLER C: LDL-apheresis in homozygous LDL-receptor-defective familial hypercholesterolemia: the Munich experience. Atheroscler Suppl 10: 21-26, 2009.

KOPPRASCH S, GRAESSLER J, BRONSTEIN SR, SCHWARZ PE, TSELMIN S, FRIND A, POBERSCHIN I, JULIUS U: Beyond lowering circulating LDL: Apheresis-induced changes of systemic oxidative stress markers by four different techniques. Atheroscler Suppl 10: 34-38, 2009.

MABUCHI H, KOIZUMI J, SHIMIZU M, KAJINAMI K, MIYAMOTO S, UEDA K, TAKEGOSHI T: Long-term efficacy of low-density lipoprotein apheresis on coronary heart disease in familial hypercholesterolemia. Hokuriku-FH-LDL-Apheresis Study Group. Am J Cardiol 82: 1489-1495, 1998.

MORTZELL H, NEWMAN ME, WITT V, DERFLER K, LEITNER G, ELOOT S, DHONDT A, DEEREN D, ROCK G, PTAK J, BLAHA M, LANSKA M, GASOVA Z, HRDLICKOVA R, RAMLOW W, ET AL.: Adverse events in apheresis: An update of the WAA registry data. Transfus Apher Sci 54: 2-15, 2016.

NAKAMURA T, KAWAGOE Y, MATSUDA T, TAKAHASHI Y, SEKIZUKA K, EBIHARA I, KOIDE H: Effects of LDL apheresis and vitamin E-modified membrane on carotid atherosclerosis in hemodialyzed patients with arteriosclerosis obliterans. Kidney Blood Press Res 26: 185-191, 2003.

POKROVSKY SN, AFANASIEVA OI, EZHOV MV: Lipoprotein(a) apheresis. Curr Opin Lipidol 27: 351-358, 2016.

RATHOUSKÁ J, JEŽKOVÁ K, NĚMEČKOVÁ I, NACHTIGAL P: Soluble endoglin, hypercholesterolemia and endothelial dysfunction. Atherosclerosis 243: 383-388, 2015.

SCHUFF-WERNER P: Clinical long-term results of H.E.L.P-apheresis (in German). Z Kardiol 92 (Suppl 3 ): III28-III29, 2003.

SOLICHOVA D, BLÁHA M, AUFARTOVÁ J, KUJOVSKÁ KRČMOVÁ L, PLÍŠEK J, HONEGROVÁ B, KASALOVÁ E, LÁNSKÁ M, URBÁNEK L, SOBOTKA L: The effect of LDL-apheresis and rheohaemapheresis treatment on vitamin E. J Nutr Sci Vitaminol 61: 105-112, 2015.

STEFANUTTI C, GIACOMO SD, VIVENZIO A, ISACCHI GC, MASELLA R, CAPRARI P, VARİ R, TARZIA A, MOSIELLO A, CANTAFORA A: Acute and long-term effects of low-density lipoprotein (LDL)-apheresis on oxidative damage to LDL and reducing capacity of erythrocytes in patients with severe familial hypercholesterolaemia. Clin Science 100: 191-198, 2001.

ŠAMÁNEK M, URBANOVÁ Z: Cholesterol and triglyceride levels and their development (in Czech). Cas Lek Cesk 136: $380-385,1997$. 
THOMPSON GR: Recommendations for the use of LDL apheresis. Atherosclerosis 198: 247-255, 2008.

WACHTER H, FUCHS D, HAUSEN A, REIBNEGGER G, WERNER ER: Neopterin as marker for activation of cellular immunity: immunologic basis and clinical application. Adv Clin Chem 27: 81-141, 1989.

WANG A, RICHHARIYA A, GANDRA SR, CALIMLIM B, KIM L, QUEK RGW, NORDYKE RJ, TOTH PP: Systematic review of low-density lipoprotein cholesterol apheresis for the treatment of familial hypercholesterolemia J Am Heart Assoc 5: e003294, 2016.

WILLIAMS RR, HUNT SC, SCHUMACHER MC, HEGELE RA, LEPPERT MF, LUDWIG EH, HOPKINS PN: Diagnosing heterozygous familial hypercholesterolemia using new practical criteria validated by molecular genetics. Am J Cardiol 72: 171-176, 1993. 